\title{
Extended criteria for liver transplantation in hepatocellular carcinoma. A retrospective, multicentric validation study in Belgium
}

\author{
Helena Degroote $^{\mathrm{a}, *, 1}$, Eduard Callebout ${ }^{\mathrm{a}, 1}$, Samuele Iesari ${ }^{\mathrm{b}, 1}$, Jeroen Dekervel ${ }^{\mathrm{c}, 1}$, \\ Jonas Schreiber $^{\mathrm{d}}$, Jacques Pirenne ${ }^{\mathrm{e}}$, Chris Verslype ${ }^{\mathrm{c}}$, Dirk Ysebaert ${ }^{\mathrm{f}}$, Peter Michielsen ${ }^{\mathrm{g}}$, \\ Valerio Lucidi $^{\mathrm{h}}$, Christophe Moreno ${ }^{\mathrm{d}}$, Olivier Detry ${ }^{\mathrm{i}}$, Jean Delwaide ${ }^{\mathrm{j}}$, Roberto Ivan Troisi ${ }^{\mathrm{k}, 1}$, \\ Jan Paul Lerut ${ }^{b}$, Hans Van Vlierberghe ${ }^{a}$, on behalf of the Be-LIAC

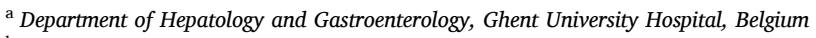 \\ ${ }^{\mathrm{b}}$ Starzl Unit Abdominal Transplantation, University Hospitals St-Luc, UCL Brussels, Belgium \\ ${ }^{\mathrm{c}}$ Department of Gastroenterology and Hepatology, University Hospital Leuven, Belgium \\ ${ }^{\mathrm{d}}$ Department of Gastroenterology, Hepatopancreatology and Digestive Oncology, Hôpital Erasme, Universite Libre de Bruxelles, Brussels, Belgium \\ ${ }^{\mathrm{e}}$ Department of Hepato-Biliary and Pancreatic Surgery, University Hospitals of Leuven, Belgium \\ ${ }_{\mathrm{f}}^{\mathrm{f}}$ Department of Hepato-Biliary and Pancreatic Surgery, University Hospital of Antwerp, Belgium \\ ${ }^{\mathrm{g}}$ Department of Hepatology and Gastroenterology, University Hospital of Antwerp, Belgium \\ ${ }^{\mathrm{h}}$ Department of Hepato-Biliary and Pancreatic Surgery, Erasme Hospital Free University of Brussels, Belgium \\ ${ }^{i}$ Department of Abdominal Surgery and Transplantation, CHU Liege (CHU ULg), Belgium \\ ${ }^{\mathrm{j}}$ Department of Hepatology and Gastroenterology, University Hospital of Liege, Belgium \\ ${ }^{\mathrm{k}}$ Dept of Human Structure and Repair, Faculty of Medicine Ghent University, Belgium \\ ${ }^{1}$ Dept. of Clinical Medicine and Surgery, Federico II University Naples, Italy
}

\section{A R T I C L E I N F O}

\section{Keywords:}

Hepatocellular carcinoma

Extended transplant criteria

Asan criteria

Up-to-7 criteria

Alpha-foetoprotein

Metroticket 2.0 model

\begin{abstract}
A B S T R A C T
Background: Recent studies indicate that a group of patients with cirrhosis receiving a liver transplantation for hepatocellular cancer (HCC) beyond the Milan Criteria (MC) can achieve a similar outcome compared to patients within these criteria. This study aims to investigate the value of the Asan critera (AC), up-to-7 criteria (UT7), French alpha-foetoprotein (AFP) model and Metroticket 2.0 (MT2.0) model compared to the MC.

Methods: 526 patients transplanted for non-metastatic HCC were analyzed. Patient groups within and beyond MC and extended criteria were determined according to radiological assessment and AFP value at listing.

Results: Overall survival (OS) and recurrence (RR) rates were similar between patients within MC and all extended criteria. Five-year OS within MC was 71.3\% compared to 70.9\% for AC, 71.4\% for UT7, 69.7\% for AFPmodel and $71.0 \%$ for MT2.0 criteria. Five-year RR within MC was $12.3 \%$ compared to $13.5 \%$ for AC, $13.0 \%$ for UT7, $14.3 \%$ for AFP-model and $13.2 \%$ for MT2.0 criteria. Patients beyond MC but within the extended criteria had tendency towards higher recurrence.

Conclusions: All validated extended criteria (AC, UT7, AFP-model and MT2.0) could be proposed as alternatives to the MC with similar outcome. Prospective data are awaited to assess recurrence beyond MC.
\end{abstract}

\section{Introduction}

In the Eurotransplant (ET) countries the gold standard for liver transplantation (LT) in patients with hepatocellular cancer (HCC) are the Milan Criteria (MC). These criteria are derived from a prospective study published in 1996 by Mazzaferro et al. which studied 48 patients with cirrhosis and small, non resectable HCC [1]. Using these criteria (1 lesion less than $5 \mathrm{~cm}$ or up to 3 lesions each not exceeding $3 \mathrm{~cm}$ at imaging, in absence of macrovascular invasion and extrahepatic metastases) results in a four-year overall and disease-free survival rates of $75 \%$ and $83 \%$ respectively $[1,2]$ which is comparable to LT in cirrhotic patients not transplanted for cancer. The MC have been validated in multiple studies [2,3]. In recent years however, the MC have been challenged because similar post-transplant overall survival (OS) and recurrence rate (RR) could be achieved with extended criteria in mostly

\footnotetext{
* Corresponding author. Department of Hepatology and Gastro-Enterology, Ghent University hospital, C.Heymanslaan 10, 9000, Ghent, Belgium.

E-mail address: Helena.degroote@uzgent.be (H. Degroote).

1 Equal contribution.
} 
retrospective cohorts. Furthermore approximately $25 \%$ of the patients classified as within MC before LT were beyond MC in the explant his-

\begin{tabular}{|ll}
\hline \multicolumn{2}{|l}{ List of abbreviations } \\
AC & Asan Medical Centre criteria \\
AFP & Alpha-foetoprotein \\
HCC & Hepatocellular carcinoma \\
LT & Liver transplantation \\
MC & Milan criteria \\
MT2.0 & Metroticket 2.0 model \\
OS & Overall survival \\
RR & Recurrence rate \\
UT7 & Up-to-7 criteria
\end{tabular}

Table 1

Patient characteristics.

\begin{tabular}{|c|c|}
\hline Demographic characteristics & Mean standard deviation \\
\hline Gender & $\begin{array}{l}407(77.4 \%) \text { male } / 119(22.6 \%) \\
\text { female }\end{array}$ \\
\hline Age (yr) & $58.7 \quad 8.1$ \\
\hline \multicolumn{2}{|l|}{ Underlying disease } \\
\hline Hepatitis B & $50(9.5 \%)$ \\
\hline Hepatitis C & $167(31.7 \%)$ \\
\hline Alcoholic liver disease & $226(43.0 \%)$ \\
\hline NAFLD & $33(6.3 \%)$ \\
\hline \multicolumn{2}{|l|}{ Pre-transplant characteristics } \\
\hline MELD & $11.4 \quad 4.2$ \\
\hline Waiting time from listing (months) & $5.7 \quad 5.7$ \\
\hline Tumor control therapy on list & $279(53.0 \%)$ \\
\hline $\mathrm{AFP}(\mathrm{ng} / \mathrm{ml})$ at listing & $99.9 \quad 539.4$ \\
\hline \multicolumn{2}{|l|}{ Radiological characteristics at listing } \\
\hline Number of lesions & 1.51 .8 \\
\hline Size of largest nodule $(\mathrm{cm})$ & $2.1 \quad 1.9$ \\
\hline \multicolumn{2}{|c|}{ Radiological characteristics at transplant } \\
\hline Number of lesions & $\begin{array}{ll}1.8 & 1.7\end{array}$ \\
\hline Size of largest nodule $(\mathrm{cm})$ & $2.5 \quad 1.9$ \\
\hline \multicolumn{2}{|l|}{ Pathological characteristics explant } \\
\hline Number of lesions & $2.9 \quad 5.2$ \\
\hline Size of largest nodule $(\mathrm{cm})$ & $2.1 \quad 2.0$ \\
\hline $\begin{array}{l}\text { Tumor differentiation (poor/ } \\
\text { undifferentiated) }\end{array}$ & $33(6.3 \%)$ \\
\hline Macrovascular invasion & $15(2.9 \%)$ \\
\hline Microvascular invasion & $156(29.7 \%)$ \\
\hline
\end{tabular}

tology. [2] The MC are being considered too strict, excluding unjustified specific subgroups who could benefit from LT. Different extended criteria were proposed based on morphometric criteria (e.g. the Asan Medical Centre criteria (AC), up-to-seven criteria (UT7) or University of California San Francisco criteria [4]) or adding a marker of biological behavior such as alpha-foetoprotein (AFP) in the French model, Metroticket 2.0 model (MT2) or Hangzhou criteria [5] (list is not exhaustive).

The extended AC allow patients with up to 6 HCC nodules eligible for transplantation. The largest tumor diameter remains $5 \mathrm{~cm}$, and there may be no gross vascular invasion. These criteria are based on a singlecenter study including 221 patients with HCC who underwent living donor LT. The 5-year OS was $76.3 \%$ and $18.9 \%$ within and beyond the AC. There was a 3-year RR of $9.1 \%$ in patients exceeding the MC but within the AC. The AC have been validated in non-living donor LT in western countries [6-8].

In 2009 Mazzaferro et al. proposed the UT7 criteria as the result of a multicenter retrospective European study with seven being the maximal allowed sum of the size of the largest tumor (in $\mathrm{cm}$ ) and the number of tumors for any given HCC (if microvascular invasion was absent). The 5year OS in this group of 283 patients was $71.2 \%$, which was not significantly different from patients within the MC. The 5-year RR for patients within the UT7 criteria was 9.1\% [9]. Recently the MT2.0 model was published incorporating AFP in the UT7 criteria [10]. For patients with HCC to have a 70\% chance of HCC-specific survival 5 years after transplantation, their level of AFP should be $<200 \mathrm{ng} / \mathrm{mL}$ and the sum of number and size of tumors should not exceed 7; if the level of AFP was $200-400 \mathrm{ng} / \mathrm{mL}$, the sum of the number and size of tumors should be 5 and if their level of AFP was $400-1000 \mathrm{ng} / \mathrm{mL}$, the sum of the number and size of tumors should be 4 .

Another promising model based on AFP, published by Duvoux et al. [11] has been implemented in France. According to this AFP-model patients with 1-3 tumors and a largest tumor diameter of $6 \mathrm{~cm}$, or with 4 lesions with a maximal diameter of $3 \mathrm{~cm}$ are considered eligible for transplantation if their AFP level is $100 \mathrm{ng} / \mathrm{mL}$. Among patients within MC, the model identified a subgroup of patients with AFP values greater than $1000 \mathrm{ng} / \mathrm{mL}$ at high risk of recurrence and reduced survival.

In this retrospective, multicentric study the aim was to further investigate the value of the Asan criteria (AC), the up-to-7 criteria (UT7), the AFP-model (AFP) and the metroticket 2.0 model (MT2.0) as recently validated extended scoring systems, compared to the MC as gold standard. For this purpose we evaluated the overall survival (OS) and recurrence rate (RR) of patients within and beyond the MC and extended criteria. The groups were defined at listing as this best reflects clinical practice. We also compared the outcome of the subgroup of patients beyond the MC, but within the extended criteria. Secondly, we defined the same groups according to the available data at transplantation to address the possible influence of bridging therapy during waiting time on our results.

\section{Patients and methods}

\subsection{Patients}

714 adult patients with a pre-operative radiological diagnosis of nonmetastatic HCC who were listed for LT from 1999 to 2016 were included in this retrospective multicentric Be-LIAC study. Due to missing data, 526 patients were finally analyzed at listing and 203 patients at transplantation.

Patients were enrolled from the 6 different transplant centers in Belgium. Forty-four percent (n 233) of patients were transplanted at the Catholic University of Louvain, 20.9\% (n 110) at University Hospital Leuven, $17.3 \%$ (n 91) at Ghent University Hospital, 10.5\% (n 55) at Erasme Hospital Free University of Brussels, 4.2\% (n 22) at University Hospital of Liege and 2.9\% (n 15$)$ at University Hospital of Antwerp.

The mean age at liver transplantation (LT) was 58.7 years. $77.4 \%$ of patients were male, $22.6 \%$ female The most common underlying chronic liver diseases were alcoholic liver disease $(43.0 \%$ of patients), hepatitis C (31.7\%), hepatitis B (9.5\%) and non-alcoholic fatty liver disease (6.3). The mean lab-MELD score at listing was 11.4 (SD: 4.2). The mean time

Table 2

Number of patients beyond and within MC or extended criteria at listing. Number of events (death and recurrence)/subgroup. P-value OS and RR between patients beyond and within MC and extended criteria.

\begin{tabular}{llllll}
\hline $\begin{array}{l}\text { At } \\
\text { listing }\end{array}$ & $\begin{array}{l}\text { Number } \\
\text { OUT/IN }\end{array}$ & $\begin{array}{l}\text { Events } \\
\text { (death) } \\
\text { OUT/IN }\end{array}$ & $\begin{array}{l}\text { p-value } \\
\text { OS }\end{array}$ & $\begin{array}{l}\text { Events } \\
\text { (recurrence) } \\
\text { OUT/IN }\end{array}$ & $\begin{array}{l}\text { p-value } \\
\text { RR }\end{array}$ \\
\hline MC & $90 / 436$ & $41 / 146$ & 0.004 & $28 / 49$ & $<0.001$ \\
AC & $41 / 485$ & $25 / 162$ & $<0.001$ & $18 / 59$ & $<0.001$ \\
UT7 & $44 / 482$ & $27 / 160$ & $<0.001$ & $20 / 57$ & $<0.001$ \\
AFP & $47 / 479$ & $22 / 165$ & 0.049 & $15 / 62$ & $<0.001$ \\
MT2.0 & $58 / 468$ & $31 / 156$ & 0.001 & $21 / 56$ & $<0.001$ \\
\hline
\end{tabular}



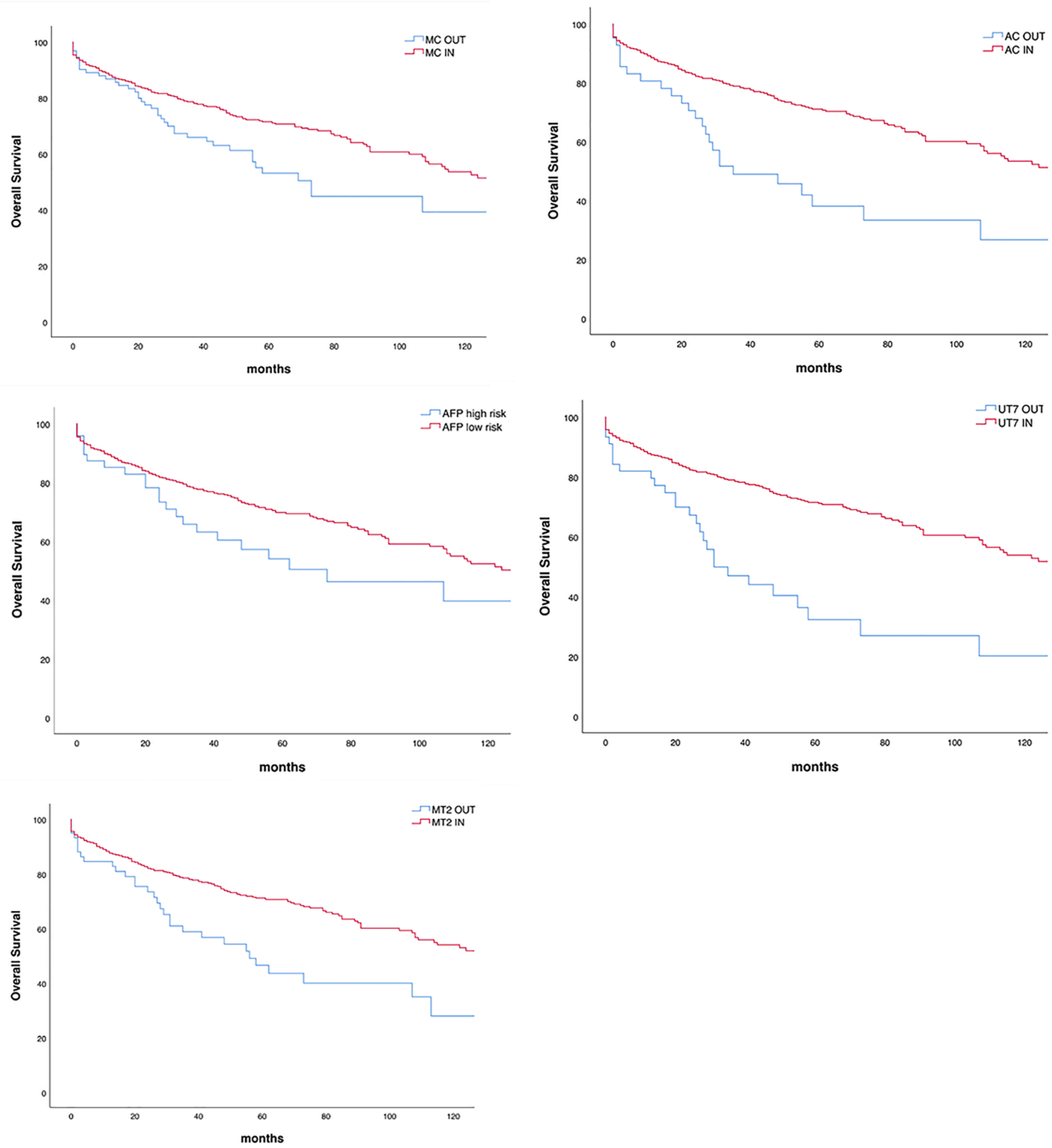

Fig. 1. Kaplan Meier curves for overall survival beyond and within MC or extended criteria.

on the waiting list until LT was 5.7 (SD: 5.7) months. Fifty-three percent of patients received bridging therapy (n 279, missing data: $14.8 \%$ ) and $15.0 \%$ were downstaged (n 79, missing data: $44.1 \%$ ). Mean follow-up after LT was 56.1 months (SD: 43.7) (Table 1).

\subsection{Data collection}

The data were retrospectively collected by 5 investigators (HD, EC, IS, IS, JS). The dataset consisted of demographic parameters, underlying 

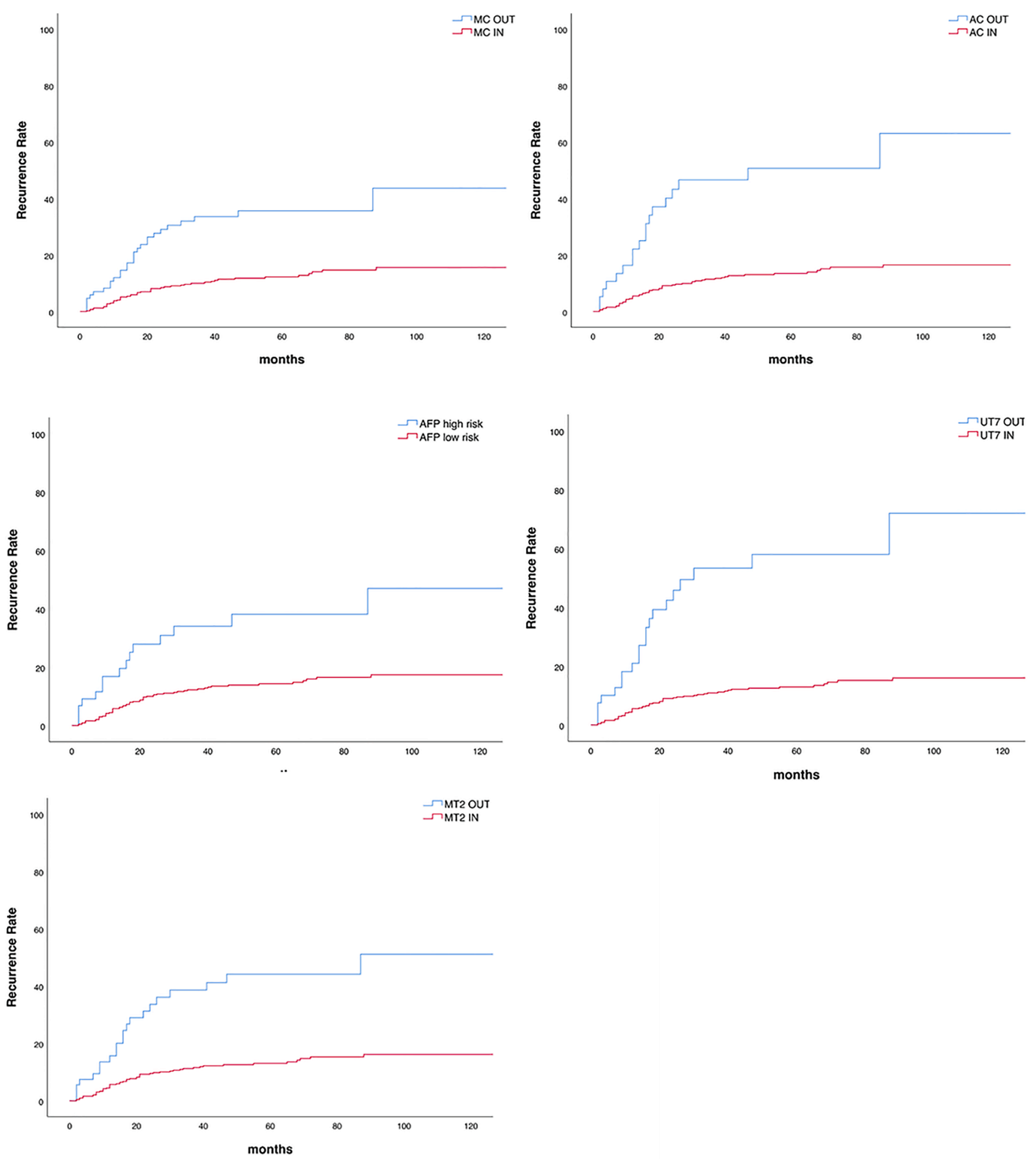

Fig. 2. Kaplan Meier curves for recurrence rate beyond and within MC or extended criteria.

Table 3

1-,3-,5- and 10-year OS and RR for patients within MC or extended criteria at listing.

\begin{tabular}{lllllllll}
\hline At listing & 1-year OS & 3-year OS & 5-year OS & 10-year OS & 1-year RR & 3-year RR & 5-year RR & 10-year RR \\
\hline MC IN & $88.0 \%$ & $78.5 \%$ & $71.3 \%$ & $53.5 \%$ & $4.1 \%$ & $10.0 \%$ & $12.3 \%$ & $15.6 \%$ \\
AC IN & $88.4 \%$ & $78.7 \%$ & $70.9 \%$ & $53.2 \%$ & $4.6 \%$ & $11.4 \%$ & $13.5 \%$ & $16.5 \%$ \\
UT7 IN & $88.3 \%$ & $78.9 \%$ & $71.4 \%$ & $53.7 \%$ & $4.4 \%$ & $10.9 \%$ & $13.0 \%$ \\
AFP IN & $88.0 \%$ & $77.6 \%$ & $69.7 \%$ & $52.2 \%$ & $4.4 \%$ & $12.3 \%$ & $14.3 \%$ & $17.4 \%$ \\
MT2.0 IN & $88.2 \%$ & $78.4 \%$ & $71.0 \%$ & $54.0 \%$ & $4.5 \%$ & $11.3 \%$ & $13.1 \%$ & $16.2 \%$ \\
\hline
\end{tabular}


Table 4

Number of patients beyond MC and within extended criteria at listing. Number of events (death and recurrence)/subgroup.

\begin{tabular}{lllll}
\hline At listing & & Number & Events (death) & Events (recurrence) \\
\hline MC OUT & AC IN & 49 & 16 & 10 \\
MC OUT & UT7 IN & 46 & 14 & 8 \\
MC OUT & AFP IN & 60 & 23 & 13 \\
MC OUT & MT2.0 IN & 44 & 13 & 8 \\
\hline
\end{tabular}

chronic liver disease, Child Turcotte Pugh score and lab-MELD at listing, time and treatment on the waiting list.

Patient groups were determined according to radiological, preoperative MC and extended criteria at listing and transplantation. The AFP level was also considered at listing and transplantation. Time of death and/or recurrence were recorded.

\subsection{Statistical analysis}

Statistical analysis was performed using SPSS statistics 23. Survivaland recurrence-rates were evaluated using Kaplan-Meier curves and groups were compared using a log-rank test. $\mathrm{P}<0.05$ was considered statistically significant.

\section{Results}

\subsection{Overall survival and recurrence rate for patients within and beyond the $M C$ and extended criteria}

At listing $17.1 \%$ of patients were beyond MC. For the extended criteria $7.8 \%, 8.3 \%, 8.9 \%$ and $11 \%$ of patients were beyond AC, UT7, AFP-model and MT2.0 criteria respectively. There was a significant higher OS and lower RR in the group of patients within MC compared to patients beyond MC $(p<0.05)$. These results were also seen for all extended criteria $(\mathrm{p}<0.05)$ (Table 2$)$.

The 1-,3-,5-, and 10-year OS and RR between the subgroup of patients within MC or within the extended criteria were found to be similar (Figs. 1 and 2). The 5-year OS for patients within MC was $71.3 \%$ compared to $70.9 \%$ for AC, $71.4 \%$ for UT7, $69.7 \%$ for AFP-model and $71.0 \%$ for MT2.0 criteria. All criteria showed an 10-year OS of more than $50 \%$. The 5-year RR for patients within MC was $12.3 \%$ and for the extended criteria: $13.5 \%$ for the AC, $13.0 \%$ for UT7, $14.3 \%$ for AFPmodel and $13.1 \%$ for MT2.0 criteria (Table 3).

At transplantation $27.0 \%$ of patients were beyond MC. For the extended criteria $6.4 \%, 11.8 \%, 15.3 \%$ and $16.7 \%$ of patients were beyond AC, UT7, AFP-model and MT2.0 criteria respectively (Table 6). The 5-year OS for patients within MC was 73.7\% compared to $73.9 \%$ for AC, $74.9 \%$ for UT7, 75.0\% for AFP-model and $75.2 \%$ for MT2.0 criteria. The 5-year RR for patients within MC was $11.4 \%$ and for the extended criteria: $12.7 \%$ for the AC, $12.2 \%$ for UT7, $13.1 \%$ for AFP-model and $11.9 \%$ for MT2.0 criteria (Table 7).

Table 5

1-,3-,5- and 10-year OS and 1-and 3-year RR for patients beyond MC and within extended criteria at listing.

\begin{tabular}{cllllll}
\hline At listing & $\begin{array}{l}\text { 1-year } \\
\text { OS }\end{array}$ & $\begin{array}{l}\text { 3-year } \\
\text { OS }\end{array}$ & $\begin{array}{l}\text { 5-year } \\
\text { OS }\end{array}$ & $\begin{array}{l}\text { 10-year } \\
\text { OS }\end{array}$ & $\begin{array}{l}\text { 1-year } \\
\text { RR }\end{array}$ & $\begin{array}{l}\text { 3-year } \\
\text { RR }\end{array}$ \\
\hline $\begin{array}{r}\text { MC OUT } \\
\text { AC IN }\end{array}$ & $91.8 \%$ & $80.9 \%$ & $66.9 \%$ & $55.2 \%$ & $8.6 \%$ & $23.7 \%$ \\
$\begin{array}{c}\text { MC OUT } \\
\text { UT7 IN }\end{array}$ & $91.2 \%$ & $82.2 \%$ & $71.5 \%$ & $60.8 \%$ & $6.8 \%$ & $18.8 \%$ \\
$\begin{array}{c}\text { MC OUT } \\
\text { AFP IN }\end{array}$ & $88.3 \%$ & $72.8 \%$ & $61.0 \%$ & $51.9 \%$ & $5.3 \%$ & $24.2 \%$ \\
$\begin{array}{c}\text { MC OUT } \\
\text { MT2.0 IN }\end{array}$ & $90.9 \%$ & $81.8 \%$ & $74.7 \%$ & $63.3 \%$ & $7.0 \%$ & $19.3 \%$ \\
\hline
\end{tabular}

Table 6

Number of patients beyond and within MC or extended criteria at transplantation. Number of events (death and recurrence)/subgroup.

\begin{tabular}{llll}
\hline $\begin{array}{l}\text { At } \\
\text { transplant }\end{array}$ & $\begin{array}{l}\text { Number OUT/ } \\
\text { IN }\end{array}$ & $\begin{array}{l}\text { Events (death) } \\
\text { OUT/IN }\end{array}$ & $\begin{array}{l}\text { Events (recurrence) } \\
\text { OUT/IN }\end{array}$ \\
\hline MC & $55 / 148$ & $20 / 37$ & $12 / 13$ \\
AC & $13 / 190$ & $7 / 50$ & $6 / 19$ \\
UT7 & $24 / 179$ & $12 / 45$ & $8 / 17$ \\
AFP & $31 / 172$ & $13 / 44$ & $7 / 18$ \\
MT2.0 & $34 / 169$ & $14 / 43$ & $9 / 16$ \\
\hline
\end{tabular}

\subsection{Overall survival and recurrence rate for patients beyond MC but} within extended criteria

Subgroup analysis compared patients within MC versus patients beyond MC but still within the extended criteria. At listing the 5-year OS for patients beyond MC, but within AC was $66.9 \%, 71.5 \%$ for UT7, $61.0 \%$ for AFP-model and $74.8 \%$ for MT2.0 criteria. All extended criteria achieved an 10-year OS of more than 50\%. The 3-year RR was $23,7 \%, 18.8 \%, 24.2 \%$ and $19.3 \%$ for the AC, UT7, AFP-model and MT2.0 criteria respectively. All recurrences occurred within the first 3-years of follow-up (Tables 3-5, Fig. 3) (See. Table 8)

At transplantation the 5-year OS for patients beyond MC, but within AC was $75.0 \%, 77.5 \%$ for UT7, $82.6 \%$ for AFP-model and $84.4 \%$ for MT2.0 criteria. The 3-year RR was 13,9\%, $11.1 \%, 18.3 \%$ and $12.5 \%$ for the AC, UT7, AFP-model and MT2.0 criteria respectively (Table 9).

\section{Discussion}

In this validation study the use of extended criteria for selecting patients with HCC in liver cirrhosis for LT was investigated by comparison with the MC as 'gold standard'. Since Mazzaferro's study in 1996, many attempts have been made to expand (and improve) these criteria. Several authors have described modest expansions of the MC in size and/or number of HCC lesions on imaging or explant, with acceptable OS and RR. Tumor differentiation and vascular invasion are also predictors of outcome after LT, but only available after pathologic examination of the specimen. Therefore surrogate markers reflecting tumor biology such as Alpha-foetoprotein (AFP) [11-13] are likely to become more important in future allocation systems. Furthermore, dynamic variables for example the waiting time on the transplant list, radiological response after locoregional therapy and the evolution in AFP on the waiting list are currently being explored [14-17].

Until now there is no uniformity concerning the most valid alternative allocation system. It is a fact however, that an increasing percentage of patients with HCC undergoes transplantation beyond conventional indications. Recently, the use of (non-specified) extended criteria has also been cited in international guidelines which leads to non-uniformed allocation protocols between different centers [18,19]. Consequently validation of extended criteria is an important and urgent need.

In the studied Be-LIAC cohort the OS was $64.4 \%$ (n 339/526) and the RR $14.6 \%$ (n 77/526) during a mean follow-up after LT of 56.1 months (SD: 43.7). Patients within MC had a 5-year OS of 71.3\% and 5year RR of $12.3 \%$. At listing $17.1 \%$ of patients were beyond MC. There

Table 7

1-,3- and 5-year OS and RR for patients within MC or extended criteria at transplantation.

\begin{tabular}{lllllll}
\hline $\begin{array}{l}\text { At } \\
\text { transplant }\end{array}$ & $\begin{array}{l}\text { 1-year } \\
\text { OS }\end{array}$ & $\begin{array}{l}\text { 3-year } \\
\text { OS }\end{array}$ & $\begin{array}{l}\text { 5-year } \\
\text { OS }\end{array}$ & $\begin{array}{l}\text { 1-year } \\
\text { RR }\end{array}$ & $\begin{array}{l}\text { 3-year } \\
\text { RR }\end{array}$ & $\begin{array}{l}\text { 5-year } \\
\text { RR }\end{array}$ \\
\hline MC IN & $89.7 \%$ & $80.9 \%$ & $73.7 \%$ & $3.7 \%$ & $10.1 \%$ & $11.4 \%$ \\
AC IN & $89.2 \%$ & $81.2 \%$ & $73.9 \%$ & $3.4 \%$ & $10.9 \%$ & $12.7 \%$ \\
UT7 IN & $90.3 \%$ & $81.9 \%$ & $74.9 \%$ & $3.0 \%$ & $10.3 \%$ & $12.2 \%$ \\
AFP IN & $90.5 \%$ & $81.2 \%$ & $75.0 \%$ & $3.8 \%$ & $12.1 \%$ & $13.1 \%$ \\
MT2.0 IN & $90.4 \%$ & $81.4 \%$ & $75.2 \%$ & $3.2 \%$ & $10.9 \%$ & $11.9 \%$ \\
\hline
\end{tabular}



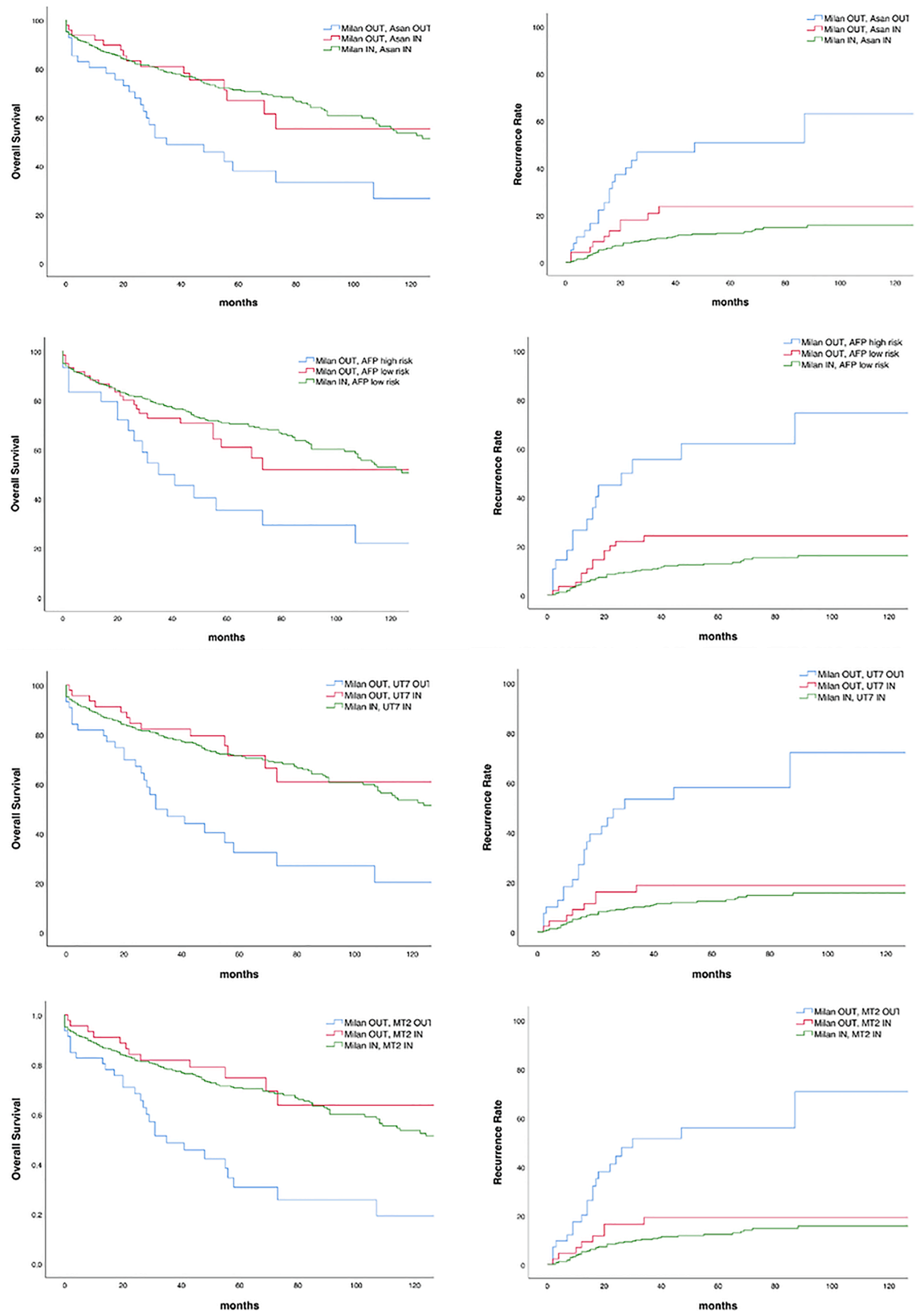

Fig. 3. Kaplan Meier curves for overall survival and recurrence rate beyond MC and within extended criteria. 
Table 8

Number of patients beyond MC and within extended criteria at transplantation. Number of events (death and recurrence)/subgroup.

\begin{tabular}{lllll}
\hline \multicolumn{2}{l}{ At transplant } & Number & Events (death) & Events (recurrence) \\
\hline MC OUT & AC IN & 42 & 13 & 6 \\
MC OUT & UT7 IN & 32 & 9 & 4 \\
MC OUT & AFP IN & 30 & 8 & 5 \\
MC OUT & MT2.0 IN & 27 & 7 & 3 \\
\hline
\end{tabular}

Table 9

1-, 3- and 5-year OS and 1-, 3- and 5-year RR for patients beyond MC and within extended criteria at transplantation.

\begin{tabular}{|c|c|c|c|c|c|c|}
\hline At transplant & $\begin{array}{l}1 \text {-year } \\
\text { OS }\end{array}$ & $\begin{array}{l}\text { 3-year } \\
\text { OS }\end{array}$ & $\begin{array}{l}5 \text {-year } \\
\text { OS }\end{array}$ & $\begin{array}{l}\text { 1-year } \\
\text { RR }\end{array}$ & $\begin{array}{l}\text { 3-year } \\
\text { RR }\end{array}$ & $\begin{array}{l}\text { 5-year } \\
\text { RR }\end{array}$ \\
\hline $\begin{array}{l}\text { MC OUT AC } \\
\text { IN }\end{array}$ & $92.7 \%$ & $82.4 \%$ & $75.0 \%$ & $2.4 \%$ & $13.9 \%$ & $17.4 \%$ \\
\hline $\begin{array}{l}\text { MC OUT } \\
\text { UT7 IN }\end{array}$ & $93.5 \%$ & $83.5 \%$ & $77.5 \%$ & $0 \%$ & $11.1 \%$ & $15.6 \%$ \\
\hline $\begin{array}{l}\text { MC OUT } \\
\text { AFP IN }\end{array}$ & $96.6 \%$ & $82.6 \%$ & $82.6 \%$ & $3.4 \%$ & $18.3 \%$ & \\
\hline $\begin{array}{l}\text { MC OUT } \\
\text { MT2.0 IN }\end{array}$ & $96.2 \%$ & $84.4 \%$ & $84.4 \%$ & $0 \%$ & $12.5 \%$ & \\
\hline
\end{tabular}

was a significant higher OS and lower RR in the group of patients within $\mathrm{MC}$ compared to patients beyond MC ( $<<0.05)$. These results were also seen for the different groups of patients within each studied extended criteria compared to patients beyond the criteria $(\mathrm{p}<0.05)$. Moreover the 1-,3-,5-, and 10-year OS and RR between patients within MC or the extended criteria were found to be similar. These results could be strengthened with similar findings at transplantation, taking into account the possible influence of bridging therapy during waiting time. Altogether the results suggest that all extended criteria can be used as an alternative for the MC. To our knowledge this is also the first large, multicentric study that can retrospectively validate the recently published MT2.0 model.

However our results must be interpreted with caution. Comparing patients within and beyond the extended criteria is not sufficient, because of a dilution effect of all the included patients within the MC. Subgroup analysis showed that patients beyond MC but within all the extended criteria had a tendency towards higher RR. This finding reflects the Metroticket paradigm introduced by Mazzaferro et al., in 2009, stating that the further the distance from conventional limits, the higher the price in terms of malignant recurrences $[3,20]$. On the other hand the 5-year OS for the subgroup of patients beyond MC but within the extended criteria was more than $50 \%$. All the criteria met the 5 -year patient survival rate of at least $61 \%$ required for an allocation system to be seen as ethically acceptable comparing the survival benefit of LT for a patient beyond the MC and the harm caused to other patients on the waiting list. However, this calculation is related to the waiting time and characteristics of donation [21]. The small number of patients and events (death as well as recurrence) in this subgroup of our cohort is too limited for reliable statistical analysis or definite conclusions. The statistical analysis was also not powered to show equivalence between the MC and the extended criteria.

Another remark is the limited number of patients at the utter limits of the extended criteria. In the studied cohort the mean diameter of the largest lesion in the subgroup beyond MC but within extended criteria was 3.3 ( SD: 1.0) for AC, 3.5 ( SD: 1.3) for UT7, 3.4 ( SD: 1.4) for AFP-model and 3.5 ( SD: 1.3) for MT2.0 criteria. This might have given an overestimation of the good performance of the extended criteria.

Considering the time point of listing for liver transplantation to validate allocation criteria best reflects clinical practice and decision making. However during the waiting time ( $\left.\begin{array}{ll}5.7 & 6.4 \text { months }\end{array}\right)$ lesions might have been falsely underestimated due to tumor growth. On the other hand many patients $(53.0 \%)$ received bridging therapy which might have overestimated lesions at listing in case of tumor shrinkage. For this reason we secondly analyzed the same groups at the nearest time point before transplantation and found similar results. The main problem with this last approach is that in daily practice standardized imaging is not performed exactly at the time of transplantation, resulting for this retrospective study in missing or less accurate data with smaller subgroups and fewer events.

When extending criteria the availability of donor organs should be taken into account. The amount of extra eligible patients for LT would be $10.1 \%$ when using AC, $9.5 \%$ for UT7, $12.5 \%$ for the AFP-model and $9.4 \%$ for the MT2.0 models. A limitation to this estimation is the inclusion of only transplanted patients in this study. A potentially substantial group of patients that are beyond MC but within extended criteria have never been transplanted and were not taken into account. For the same reason we have no data about the dropout rate on the waiting list.

Finally, extending criteria should not be the only field that merit attention. Other options to optimize patient survival and reduce the RR after LT should be looked at such as pre-operative imaging techniques using PET-CT scan [22], the use of mTOR inhibitors [23-25] as immunosuppressive regimen and most importantly the benefit of locoregional therapies with the proper assessment and timing of response [26-28]. In this regard the latest EASL Clinical Practice Guidelines (2018) state that LT for patients beyond MC can be considered after successful downstaging to within MC within defined protocols [17].

Altogether this study again urges the ongoing debate whether it is still too early to expand beyond the MC. In the variety of published criteria there is not yet a consensus on which parameters to use. It is likely that current proposals will need modifications in the next years and that boundaries will be pushed further in every new trial. For example the extended Toronto criteria include patients with any size or number of tumors for transplantation (since 2004) provided they do not have systemic cancer-related symptoms, extrahepatic disease, vascular invasion, or poorly differentiated tumors on tumor biopsy of the largest lesion [29]. We are limited by the fact that current knowledge is almost completely based on retrospective validation studies. Prospective data from centers already using extended criteria in real life are still awaited. On the other hand, by using the MC, we might deny good candidates for transplantation a possible curative treatment. It is of utmost importance not to miss an opportunity to uniform the used allocation criteria.

\section{Conclusion}

In this Be-LIAC multicenter study similar overall survival and recurrence rate were observed in patients within $\mathrm{MC}$ and all extended criteria (AC, UT7, AFP-model and MT2.0). Therefore these criteria could be considered as alternative selection criteria for liver transplantation in HCC patients with an underlying liver disease. Prospective studies are warranted as an increased recurrence rate in the subgroup of patients beyond MC has been observed in this cohort.

\section{Authorship}

HD, EC, IS, JD, JS: data acquisition, HD, EC, IS, JD: designed the research and wrote the manuscript, all authors: read, edited the manuscript and approved the final manuscript.

\section{Funding sources}

This research did not receive any specific grant from funding agencies in the public, commercial, or not-for-profit sectors.

\section{Declaration of competing interest}

No conflict of interest reported in relation to the presented work. 


\section{Acknowledgements}

The original idea for this article originated from Be-LIAC meetings. We want to thank all authors for the cooperation and support. The author's responsibilities were as follows - HD, EC, JD, JS: data acquisition, HD, EC, JD: designed the research and wrote the manuscript, all authors: read, edited the manuscript and approved the final manuscript.

\section{References}

[1] V. Mazzaferro, E. Regalia, R. Doci, S. Andreola, A. Pulvirenti, F. Bozzetti, et al., Liver transplantation for the treatment of small hepatocellular carcinomas in patients with cirrhosis, N. Engl. J. Med. 334 (11) (1996) 693-699.

[2] V. Mazzaferro, S. Bhoori, C. Sposito, M. Bongini, M. Langer, R. Miceli, et al., Milan criteria in liver transplantation for hepatocellular carcinoma: an evidence-based analysis of 15 years of experience, Liver Transplant. 17 (Suppl 2) (2011) S44-57.

[3] G. Germani, K. Gurusamy, M. Garcovich, C. Toso, G. Fede, A. Hemming, et al., Which matters most: number of tumors, size of the largest tumor, or total tumor volume? Liver Transplant. 17 (Suppl 2) (2011) S58-66.

[4] F.Y. Yao, L. Xiao, N.M. Bass, R. Kerlan, N.L. Ascher, J.P. Roberts, Liver transplantation for hepatocellular carcinoma: validation of the UCSF-expanded criteria based on preoperative imaging, Am. J. Transplant. 7 (11) (2007) 2587-2596.

[5] Z. Qu, Q. Ling, J. Gwiasda, X. Xu, H. Schrem, J. Beneke, et al., Hangzhou criteria are more accurate than Milan criteria in predicting long-term survival after liver transplantation for HCC in Germany, Langenbeck's Arch. Surg. 403 (5) (2018) 643-654.

[6] S.G. Lee, S. Hwang, D.B. Moon, C.S. Ahn, K.H. Kim, K.B. Sung, et al., Expanded indication criteria of living donor liver transplantation for hepatocellular carcinoma at one large-volume center, Liver Transplant. 14 (7) (2008) 935-945.

[7] D. Balci, M. Dayangac, O. Yaprak, B. Akin, C. Duran, R. Killi, et al., Living donor liver transplantation for hepatocellular carcinoma: a single center analysis of outcomes and impact of different selection criteria, Transpl. Int. 24 (11) (2011) 1075-1083.

[8] I. Bonadio, I. Colle, A. Geerts, P. Smeets, G. Berardi, M. Praet, et al., Liver transplantation for hepatocellular carcinoma comparing the Milan, UCSF, and Asan criteria: long-term follow-up of a Western single institutional experience, Clin. Transplant. 29 (5) (2015) 425-433.

[9] V. Mazzaferro, J.M. Llovet, R. Miceli, S. Bhoori, M. Schiavo, L. Mariani, et al., Predicting survival after liver transplantation in patients with hepatocellular carcinoma beyond the Milan criteria: a retrospective, exploratory analysis, Lancet Oncol. 10 (1) (2009) 35-43.

[10] V. Mazzaferro, C. Sposito, J. Zhou, A.D. Pinna, L. De Carlis, J. Fan, et al., Metroticket 2.0 model for analysis of competing risks of death following liver transplantation for hepatocellular carcinoma, Gastroenterology (2017).

[11] C. Duvoux, F. Roudot-Thoraval, T. Decaens, F. Pessione, H. Badran, T. Piardi, et al., Liver transplantation for hepatocellular carcinoma: a model including alphafetoprotein improves the performance of Milan criteria, Gastroenterology 143 (4) (2012) 986-994, e3; quiz e14-5.

[12] E. Vibert, D. Azoulay, E. Hoti, S. Iacopinelli, D. Samuel, C. Salloum, et al., Progression of alphafetoprotein before liver transplantation for hepatocellular carcinoma in cirrhotic patients: a critical factor, Am. J. Transplant. 10 (1) (2010) $129-137$.

[13] C. Toso, S. Asthana, D.L. Bigam, A.M. Shapiro, N.M. Kneteman, Reassessing selection criteria prior to liver transplantation for hepatocellular carcinoma utilizing the Scientific Registry of Transplant Recipients database, Hepatology 49 (3) (2009) 832-838.

[14] Q. Lai, D. Nicolini, M. Inostroza Nunez, S. Iesari, P. Goffette, A. Agostini, et al., A novel prognostic index in patients with hepatocellular cancer waiting for liver transplantation: time-radiological-response-alpha-fetoprotein-inflammation (TRAIN) score, Ann. Surg. (2016).

[15] Q. Lai, A. Vitale, S. Iesari, A. Finkenstedt, G. Mennini, G. Spoletini, et al., Intentionto-treat survival benefit of liver transplantation in patients with hepatocellular cancer, Hepatology 66 (6) (2017) 1910-1919.

[16] K.J. Halazun, P. Tabrizian, M. Najjar, S. Florman, M. Schwartz, F. Michelassi, et al., Is it time to abandon the milan criteria?: results of a bicoastal US collaboration to redefine hepatocellular carcinoma liver transplantation selection policies, Ann. Surg. 268 (4) (2018) 690-699.

[17] O. Ciccarelli, Q. Lai, P. Goffette, P. Finet, C. De Reyck, F. Roggen, et al., Liver transplantation for hepatocellular cancer: UCL experience in 137 adult cirrhotic patients. Alpha-foetoprotein level and locoregional treatment as refined selection criteria, Transpl. Int. 25 (8) (2012) 867-875.

[18] P.A. Clavien, M. Lesurtel, P.M. Bossuyt, G.J. Gores, B. Langer, A. Perrier, et al., Recommendations for liver transplantation for hepatocellular carcinoma: an international consensus conference report, Lancet Oncol. 13 (1) (2012) e11-22.

[19] European Association for the Study of the Liver, Electronic address eee, European association for the study of the L. EASL clinical practice guidelines: management of hepatocellular carcinoma, J. Hepatol. 69 (1) (2018) 182-236.

[20] F.Y. Yao, Liver transplantation for hepatocellular carcinoma: beyond the Milan criteria, Am. J. Transplant. 8 (10) (2008) 1982-1989.

[21] M.L. Volk, S. Vijan, J.A. Marrero, A novel model measuring the harm of transplanting hepatocellular carcinoma exceeding Milan criteria, Am. J. Transplant.: Off. J. Am. Soc. Transplant. Am. Soc. Transplant Surg. 8 (4) (2008) 839-846.

[22] O. Detry, L. Govaerts, A. Deroover, M. Vandermeulen, N. Meurisse, S. Malenga, et al., Prognostic value of (18)F-FDG PET/CT in liver transplantation for hepatocarcinoma, World J. Gastroenterol. 21 (10) (2015) 3049-3054.

[23] E. Melloul, M. Lesurtel, B.I. Carr, P.A. Clavien, Developments in liver transplantation for hepatocellular carcinoma, Semin. Oncol. 39 (4) (2012) 510-521.

[24] E.K. Geissler, A.A. Schnitzbauer, C. Zulke, P.E. Lamby, A. Proneth, C. Duvoux, et al., Sirolimus use in liver transplant recipients with hepatocellular carcinoma: a randomized, multicenter, open-label phase 3 trial, Transplantation 100 (1) (2016) $116-125$.

[25] J. Lerut, S. Iesari, M. Foguenne, Q. Lai, Hepatocellular cancer and recurrence after liver transplantation: what about the impact of immunosuppression? Transl. Gastroenterol. Hepatol. 2 (2017) 80.

[26] Q. Lai, A. Vitale, M. Rossi, U. Cillo, J. Lerut, European hepatocellular cancer liver transplantation study G. Which is the true role of bridging therapies for HCC patients waiting for liver transplantation? Ann. Surg. (2017).

[27] N. Mehta, J. Guy, C.T. Frenette, J.L. Dodge, R.W. Osorio, W.B. Minteer, et al., Excellent outcomes of liver transplantation following down-staging of hepatocellular carcinoma to within milan criteria: a multicenter study, Clin. Gastroenterol. Hepatol.: Off Clin. Prac. J. Am. Gastroenterol. Assoc. 16 (6) (2018) 955-964.

[28] W.C. Chapman, S. Garcia-Aroz, N. Vachharajani, K. Fowler, N. Saad, Y. Lin, et al., Liver transplantation for advanced hepatocellular carcinoma after downstaging without up-front stage restrictions, J. Am. Coll. Surg. (2017).

[29] G. Sapisochin, N. Goldaracena, J.M. Laurence, M. Dib, A. Barbas, A. Ghanekar, et al., The extended Toronto criteria for liver transplantation in patients with hepatocellular carcinoma: a prospective validation study, Hepatology 64 (6) (2016) 2077-2088. 